\title{
A política dos sentimentos e a questão social no século XIX ${ }^{1}$
}

Ana Paula Vosne Martins*

Resumo: O artigo analisa a questão social conforme definida no século XIX pela filantropia a partir da mobilização coletiva e política dos sentimentos. Busca-se compreender as diferentes motivações de discursos e práticas reformadores e benevolentes, procurando reconstruir seus fundamentos sociais e morais, articulados a uma reflexão sobre os sentimentos políticos acionados no enfrentamento da questão social.

Palavras-chave: Filantropia. Sentimentos. Poder. Questão social.

Vivemos uma época de expansão do setor de atividades sem fins lucrativos e das organizações não-governamentais. São organizações com origens as mais diversas, mas em comum se destacam do setor público e do setor privado pelo protagonismo de associações, institutos e outras formas de organização da sociedade civil num amplo espectro de ações (GOHN, 2003; 2010). Deste conjunto diversificado de organizações sociais destacamos aquelas que se dedicam às chamadas causas humanitárias, geralmente envolvidas com problemas sociais de toda ordem. Mesmo com o crescente investimento neste setor de atividades não lucrativas e a ampliação de pessoas interessados em participar nas campanhas humanitárias,

"Doutora em História pela Universidade Estadual de Campinas - UNICAMP. Professora associada do Departamento de História da Universidade Federal do Paraná. Bolsista de Produtividade do CNPq. E-mail: ana_martins@uol.com.br 
órgãos internacionais como UNICEF (Fundo das Nações Unidas pela Infância), FAO (Organização das Nações Unidas para Alimentação e Cultura), Médicos sem Fronteiras, Cruz Vermelha, Save the Children, entre outros, continuam a alertar para as recorrentes crises, geralmente num cruel pano de fundo de violência extrema, bem como a crescente dificuldade que muitos - inclusive o Brasil - terão para alcançar os oito objetivos do milênio. ${ }^{2}$

Tais alertas se fazem acompanhar da divulgação de imagens comovedoras nos meios de comunicação, acompanhadas dos dados estatísticos que não deixam margem para qualquer dúvida quanto à fragilidade e limitação dos esforços humanitários. No entanto, é inegável seu efeito no despertar, mesmo que temporário, da solidariedade e dos sentimentos humanitários, mas principalmente no incansável trabalho voluntário e/ou remunerado de homens e mulheres ligados a estas e tantas outras organizações sociais sem fins lucrativos que são tão presentes e fundamentais no enfrentamento destas crises.

Neste artigo não tratamos desta forma contemporânea de protagonismo das organizações sociais. Lembramos do seu importante papel num mundo globalizado e em rede não para estabelecer arbitrariamente uma linha de continuidade entre antigas formas de associativismo civil e as organizações contemporâneas. Nosso interesse reside mais na mobilização coletiva e política dos sentimentos que se faz necessária no presente como se fez também em outros contextos históricos.

Apesar das diferenças de vocabulário, objetivos e da visibilidade numa época de comunicação/mobilização globalizada, a ação humanitária e os sentimentos que suscita se enraíza numa experiência muito antiga, a da caridade e da filantropia, ou numa experiência sentimental ligada aos cuidados dispensados aos sofredores e necessitados, objeto da análise deste artigo. A partir do momento em que as necessidades e carências dos "desgraçados" ou "desafortunados" deixaram de ser explicadas como resultado da ordem natural das coisas, de fatalidades ou do pecado e que seus atores principais os pobres - entraram na cena política no contexto das revoluções dos séculos XVIII e XIX, começaram a ser formulados discursos em torno de uma nova questão, a questão social (ARENDT, 1988). 
Estes discursos traduziram para o léxico racionalista-iluminista percepções e sentimentos até então associados ao ethos cristão a respeito do sofrimento dos miseráveis, dando uma nova inteligibilidade moral e racional às causas e aos efeitos da pobreza. A reflexão e o sentimento suscitados pela pobreza e pelos miseráveis estão na origem do que podemos chamar de secularização dos cuidados, pontuada por uma ação racional e benevolente envolvendo homens e mulheres na filantropia, sem uma necessária justificação religiosa para a ação social. Os cuidados com os necessitados que até meados do século XVIII eram dispensados a partir de um quadro moral religioso, passaram a integrar outra moralidade associada à razão e à sensibilidade (DUPRAT, 1993).

$\mathrm{O}$ que fazer com os pobres, ou melhor, o que fazer com os pobres para evitar que eles se rebelassem contra as suas condições históricas, lição aprendida das jornadas revolucionárias? Nos quadros ideológicos do liberalismo político e econômico não havia solução para este problema, a não ser enquadrar os pobres na disciplina do trabalho, transformando-os em operários. Esta solução agravou as injustiças e as desigualdades, como também as péssimas condições de vida dos trabalhadores e de suas famílias, afinal como muitos observadores sociais do século XIX concluíram, o problema não estava na falta de morigeração dos pobres, mas na organização do trabalho e na desestruturação de formas comunitárias e familiares de produção. A organização capitalista da produção e da exploração do trabalho estava na origem da pauperização não de alguns trabalhadores "desajustados", mas como bem observou Engels, da "imensa maioria do povo", de toda a classe trabalhadora (1985, p. 27). Para Engels não havia como resolver esta questão nos quadros políticos e morais do liberalismo. A exploração e a miséria produzidas e agravadas pelo capitalismo seriam ultrapassadas somente pela ação revolucionária dos trabalhadores.

Entre as polarizações da questão social no século XIX outros discursos começaram a ser formulados e outras práticas se organizaram num viés político reformador, acionando para o seu enfrentamento referências morais e culturais tradicionais e bem conhecidas: a religião e a antiga prática da benevolência. 
É para estes discursos e práticas reformadores e benevolentes que voltamos nossa atenção neste artigo, procurando não só reconstruir seus fundamentos morais e práticos, mas também propor uma reflexão sobre os sentimentos políticos relativos à questão social conforme ela se apresentava aos olhos e às emoções dos sujeitos das classes favorecidas. Alinhando-nos às considerações realizadas por Pierre Ansart (2007) procuramos analisar a questão social por meio da mobilização dos "afetos coletivos" e dos "sentimentos compartilhados" com vistas ao gerenciamento político do social.

\section{A questão social e a expansão da benevolência}

Numa das salas reservadas à pintura realista do século XIX no imponente e belo Museu Palácio Belvedere em Viena há alguns exemplares de um dos mais bem sucedidos artistas austríacos da época, Ferdinand Georg Waldmüller (1793-1865), responsável pela fama e difusão do estilo biedermeier. Seus quadros retratam paisagens e cenas cotidianas com grande realismo, domínio técnico e colorido, tendo sido um atento retratista de sentimentos como o amor, a piedade, a amizade, a bondade, agradando o gosto burguês mais intimista e sentimental que começara a preponderar não só na imperial Viena da metade do século XIX, mas também em outros lugares da Europa e das Américas.

A figura abaixo mostra uma cena típica dos quadros de Waldmüller, com muitas personagens expressando emoções vívidas, quase como se fosse uma fotografia, um instantâneo de uma cena coletiva na qual se observam detalhes das expressões de cada rosto, o movimento de cada gesto. O pintor retrata uma cena com pessoas de diferentes classes e categorias sociais unidas num evento de caridade cristã na qual os benemerentes se encontram com os beneficiados no dia comemorativo de São Miguel com a finalidade de distribuir roupas de inverno para crianças pobres na paróquia vienense de Spittelberg. 
Figura 1. Children of poor parents get winter clothes from the community on Spittelberg on Saint Michel Day (1857), de Ferdinand Georg Waldmüller. Óleo sobre tela.

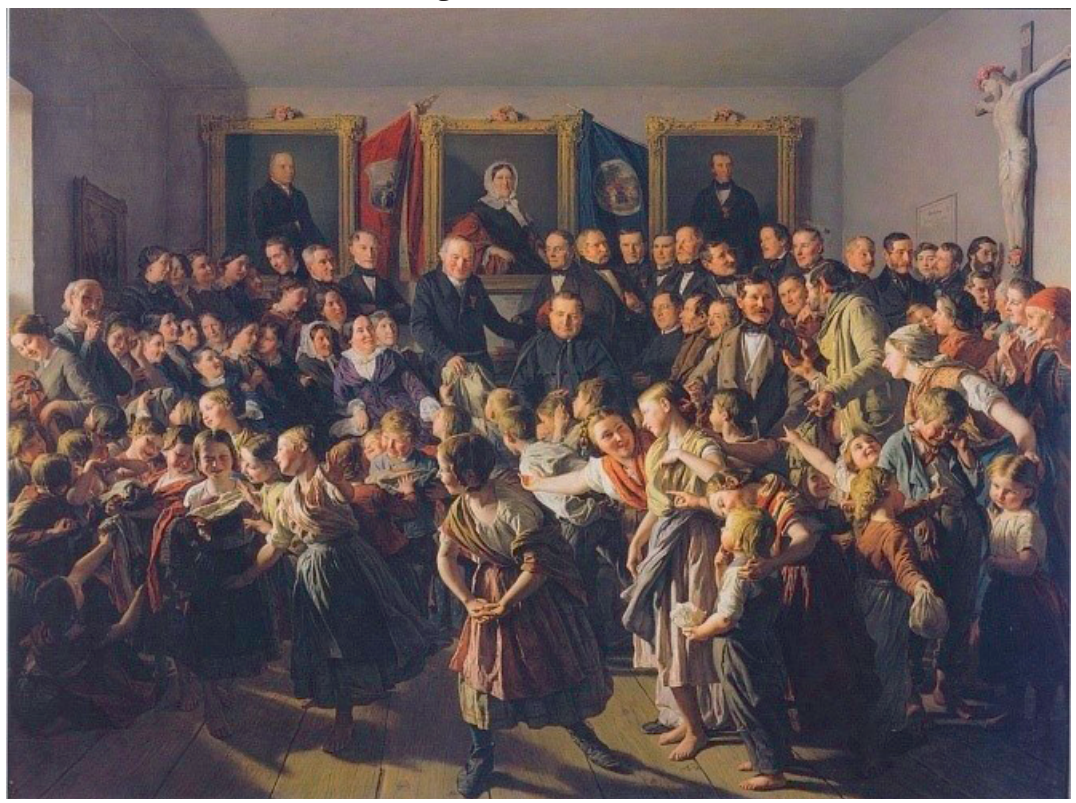

Fonte: Acervo do Belvedere Palace and Museum, Viena, Áustria.

Propomos uma leitura deste quadro seguindo muito de perto o procedimento da análise discursiva, ou seja, tomar a representação pictórica pelos seus sentidos e significados, tendo em vista o projeto estético realista de recriar o real (BARTHES, 1984). O quadro está dividido em "camadas" ou linhas hierárquicas, estando à frente, de forma um tanto quanto desorganizada, as crianças pobres, das quais quase se pode ouvir o ruído. Algumas riem, outras conversam e demonstram seu contentamento, banhadas pela luz que entra pela porta à esquerda; um menino chora no canto direito, consolado por outras duas crianças. Junto a elas, na mesma linha, vemos mulheres, algumas idosas, outras mais jovens, observando e participando da cena com expressões de nítida satisfação e agradecimento. 
$\mathrm{Na}$ camada acima deste rebuliço dos pobres estão homens e mulheres benemerentes, os patrocinadores da dádiva cristã, todos bem ordenados, com uma preponderância masculina do lado direito e feminina no lado esquerdo. Percebe-se que são pessoas das classes favorecidas, seja pelo modo como estão trajados, respeitando os códigos burgueses de sobriedade, seja pela expressão de seus rostos e corpos, quase todos sentados e demonstrando uma satisfação contida ao ver que sua dádiva foi bem recebida. Ao centro, dividindo os dois grupos principais está o clérigo, sentado junto a um paroquiano que parece ser o distribuidor das roupas. Ele olha com condescendência, como quem que dirige a cena. Acima, na última linha estão três retratos: o retrato central de uma dama, ladeado por dois retratos de cavalheiros, provavelmente fundadores da obra de caridade daquela paróquia. No lado direito e masculino do quadro, encimando a cena de caridade, o Crucificado, a abençoar as boas ações.

Esta imagem pode não chamar a atenção em nossos dias, tanto que os visitantes do museu passam desatentos ao quadro, buscando por obras mais famosas e vanguardistas, como as telas de Gustav Klimt ou então os retratos da imperatriz Sissi. No entanto, os observadores burgueses do século XIX entendiam a cena e podem até mesmo ter se comovido com ela, afinal Waldmüller retratou não só um grupo de caridosos cristãos de uma comunidade vienense em particular, mas o que podemos chamar de "espírito" de uma época, a época da benevolência, como bem a definiu o historiador britânico Asa Briggs (1999).

Os sentimentos compassivos e as práticas de caridade representados na pintura de Waldmüller compunham um quadro mais amplo de referências morais e políticas bastante disseminadas pela piedade cristã, de longa história, e pelo humanitarismo associado ou não às motivações religiosas, quadro este que impulsionou a criação de instituições caritativo-filantrópicas a partir de meados do século XVIII nas sociedades ocidentais, parte menos estudada do processo civilizador.

A historiografia que tratou do reordenamento social advindo das transformações econômicas e políticas da Revolução Industrial e da configuração de uma sociedade capitalista com seus contornos mais definidos no século XIX deu bastante destaque às tensões e 
aos conflitos de classe, como também às diferentes interpretações dadas pelo pensamento filosófico e social da época a respeito das antinomias do capitalismo, particularmente o fenômeno da pobreza (HOBSBAWM, 1997; 2000; THOMPSON, 1987; HIMMELFARB, 1988; GEREMEK, 1995). Desde meados do século XIX ocorreu um intenso debate que remontava ao século anterior cujo tema motivador era compreender ou explicar como um sistema produtivo então considerado como o mais racional para a produção da riqueza continuava a conviver, senão mesmo a ampliar a pobreza e a miséria em níveis cada vez mais alarmantes.

O debate sobre a questão social envolveu sujeitos de diferentes orientações políticas e ideológicas ampliando-se no século XIX quando então este debate se sobrepôs aos conflitos político-ideológicos. Entram em cena os socialistas, as organizações das classes trabalhadoras, mas também um grupo bastante heterogêneo de sujeitos dificilmente categorizados pela simples oposição entre liberais e conservadores, composto por homens e mulheres que começaram a se envolver no debate sobre a questão social não somente no terreno das ideias políticas, mas defendendo a necessidade de uma ação mitigatória, quando não reformista, contra os efeitos indesejados do progresso. Eram indivíduos de extração social burguesa e aristocrática que poderiam ter sido representados por Waldmüller e que compartilhavam o mesmo ethos compassivo ou paternalista das classes privilegiadas, interpretado diferentemente pelos observadores da época e também pela historiografia.

Convém determo-nos mesmo que superficialmente no cenário da pobreza que tanto motivou ou sensibilizou os participantes do debate em torno da questão social. Os pobres representados por Waldmüller certamente são bastante idealizados com suas faces coradas e risonhas, alguns descalços e com roupas desgastadas, mas prevalece o aspecto saudável e vivaz reforçado pela infância. No entanto, em outras pinturas de Waldmüller a idealização foi superada pelo realismo social de um mendigo idoso a receber uma vasilha de sopa numa casa humilde (Charity, 1865), ou de uma mãe derrotada pelo cansaço ao velar pelo filho que dorme numa cama, desfalecida no chão de um quarto muito pobre (Depleted Power, 1854). ${ }^{3}$ 
Apesar das idealizações ou do seu extremo oposto, a associação da pobreza e dos pobres com o submundo da vagabundagem e da delinqüência, a realidade social do mundo dos pobres se impunha nos grandes centros urbanos industrializados e numa sociedade agrária em crise, afetada pelas ondas migratórias especialmente de pessoas jovens em direção às cidades e aos empregos (GEREMEK, 1995). É certo que a visibilidade andrajosa dos mendigos antecede em muito a época do capitalismo e do sistema de fábricas, mas no século XIX o problema adquiriu uma dimensão política muito mais grave porque não se tratava mais de bandos de mendigos e incapazes ou de sujeitos individualizados pelo estigma da vagabundagem a perambular pelas cidades, mas de famílias inteiras de trabalhadores na miséria vivendo em condições abjetas. As antinomias do capitalismo não se restringiam ao debate ideológico que opunha moralistas e socialistas a defensores intransigentes do livre mercado, mas se tornavam visíveis dentro das fábricas, nas ruas e vielas dos bairros de trabalhadores, nas imediações das igrejas e nas portas das obras de caridade.

Aos olhos dos observadores das classes privilegiadas começava a se tornar cada vez mais incômodo tanta riqueza convivendo com a pobreza e a miséria crescentes nas cidades que viviam o "surto de progresso". Esse é, portanto, o cenário no qual se desenvolveu a questão social no século XIX, esboçado inicialmente na Inglaterra a partir do século XVIII, mas que assumiu uma nova dimensão devido ao tom político e emocional com o qual a questão social se revestiu em outros países também.

Médicos e funcionários dos governos locais começaram um minucioso trabalho de investigação social, visitando fábricas, minas, bairros populares e as moradias dos trabalhadores, realizando estatísticas, escrevendo relatórios e propondo intervenções, mesmo que modestas, por parte dos poderes públicos. Boa parte deste material serviu para fundamentar os argumentos nos debates em torno das primeiras leis sociais da Inglaterra no sentido de regulamentar as condições de trabalho nas minas de carvão e nas fábricas têxteis entre as décadas de 1830 e 1840 . É possível ter uma pequena amostra deste material de investigação no livro de Engels supracitado sobre a classe trabalhadora na Inglaterra, publicado em 1845. Engels lançou mão desta documentação para reforçar os seus argumentos em 
torno das condições de vida dos trabalhadores, além da imprensa, que também publicava artigos de médicos, funcionários, clérigos e filantropos, nos quais se narravam as péssimas condições de moradia, a escassa alimentação, o vestuário insuficiente e miserável e as doenças que abatiam especialmente as crianças.

Escritores e periodistas também desempenharam importante papel como observadores e críticos sociais, retratando o cotidiano violento e desumano do pauperismo, agravado pela condução política conservadora e autoritária, especialmente na Inglaterra com a institucionalização dos pobres nas workhouses, a estigmatização e o abandono à própria sorte de milhares de pessoas decorrente da Nova Lei dos Pobres, de 1834, que punha fim ao velho sistema paroquial de proteção aos pobres existente desde o tempo dos Tudor e dos Stuart (POLANY, 2000; HOBSBAWM, 2000).

Charles Dickens e Elizabeth Gaskell descreveram de forma intensamente realista em seus romances os efeitos do pauperismo na vida de crianças, homens e mulheres trabalhadores, especialmente após a Nova Lei dos Pobres. Fome, doenças, crescente mortalidade infantil, insalubridade nas moradias, estigmatização social, desesperança, compunham de maneira dramática a questão social:

Uma fé cega no progresso econômico espontâneo havia se apossado da mentalidade das pessoas e, com o fanatismo de sectários, os mais esclarecidos pressionavam em favor de uma mudança na sociedade, sem limites, nem regulamentações. Os efeitos causados na vida das pessoas foram terríveis, quase indescritíveis. A sociedade humana poderia ter sido aniquilada, de fato, não fosse a ocorrência de alguns contramovimentos protetores que cercearam a ação desse mecanismo autodestrutivo (POLANY, 2000, p. 97-98).

Entre estes contramovimentos destacamos a organização política dos trabalhadores, a crítica política e os projetos sociais elaborados pelos socialistas desde o começo do século XIX, o amplo movimento por reformas sociais, cujo espectro ideológico ia das Casas de Indústria de Jeremy Bentham, passando pelas ligas e associações de inspiração religiosa para a educação dos trabalhadores e de seus filhos, ao terreno ainda mais amplo da caridade e 
da filantropia. É sobre este último que vamos nos deter um pouco mais detalhadamente.

Incluímos a ação caritativo-filantrópica no rol dos movimentos reformistas do século XIX embora seja necessário esclarecer que as motivações que levaram tantos homens e mulheres a se envolver com os cuidados aos necessitados nem sempre tiveram intenções reformistas, mas sim mitigatórias; visavam mais o alívio e o apaziguamento do que a transformação social. No entanto, consideramos que o movimento caritativo-filantrópico que tomou corpo desde as décadas de 1830 e 1840 na Inglaterra, depois na França, se espalhando por outros países inclusive além do Atlântico, deve ser pensado como parte de um amplo movimento reformista, se não propriamente da sociedade, mas de algumas instituições e principalmente do cotidiano das pessoas que deveriam receber os cuidados e os benefícios dispensados a fim de melhorarem suas vidas.

É preciso antes fazer uma distinção entre as ações sociais de caridade e as ações filantrópicas. A caridade é mais do que um ato de doação àquele que necessita, pois na formulação original do pensamento cristão trata-se de uma virtude, do fim último da vida espiritual, sendo definida por Tomas de Aquino como uma virtude teologal, da mesma forma que a fé e a esperança. No entanto, na condução prática da vida dos cristãos a dimensão teológica da caridade como amor a Deus talvez fosse mais complexa para ser vivida, requerendo sutileza de interpretação, inclusive do que se entendia pela palavra amor. A dimensão mais facilmente compreendida da caridade diz respeito aos atos, às formas de expressão desse amor a Deus e ao próximo, conforme expresso nos textos evangélicos. Dos atos de caridade, os mais conhecidos e praticados são os atos exteriores como a beneficência, ato de bem fazer ao outro, sendo a esmola sua realização mais conhecida e praticada (AQUINO, 1990).

A prática da caridade como doação de esmolas aos pobres é muito antiga, tendo ocupado um importante lugar na economia moral das sociedades pré-industriais, tanto como forma de adequação à moralidade cristã, mas igualmente como parte da manutenção das relações de dominação das classes proprietárias que mantinham os "seus pobres" e deles recebiam ou deveriam receber reconhecimento e deferência. O velho sistema paternalista 
da caridade por distribuição de víveres e esmolas teve nas Igrejas Católica e Protestante um importante elo de comunicação entre o clero, a moralidade cristã e os fiéis, como podemos observar no quadro de Waldmüller. Embora a caridade não dependesse do clero para ser exercida, afinal podia ser praticada sem intermediários e de maneira anônima, padres e pastores não deixavam de lembrar seus rebanhos cristãos de que a caridade era não só uma virtude, mas do ponto de vista moral um dever e como tal devia estar no centro da vida cristã.

A caridade sustentou as mais diversas ações mitigatórias como a criação de hospitais, das Misericórdias, de abrigos para crianças órfãs, de escolas para os filhos da pobreza, bem como ações temporárias como atendimento aos doentes em épocas de epidemias e de guerras, bem como a distribuição de alimentos e roupas em períodos de crise, escassez e de fome (GEREMEK, 1995).

A palavra filantropia é de uso mais recente, aparecendo entre os séculos XVII e XVIII, sendo de uso corrente no século seguinte. Seu léxico e quadro de referências morais não são religiosos, embora não se possa separar de forma definitiva a caridade da filantropia, pois muitos filantropos e filantropas foram notáveis membros de suas comunidades religiosas, sobrepondo ações motivadas pela caridade com a moderna prática da filantropia. A filantropia foi definida e praticada pelos indivíduos modernos como uma ação racional para expressar solidariedade e simpatia pelos que sofrem, mas também por ser expressão das virtudes da benemerência e da sociabilidade, tão caras aos homens e mulheres ilustrados (DUPRAT, 1993).

Mais do que a religião o quadro de referências conceituais e morais da filantropia se encontra na filosofia moral do século XVIII, particularmente nos escritos de Adam Smith e Jean-Jacques Rousseau.

Para Rousseau (2000) a mais importante, senão a única virtude natural dos seres humanos era a piedade, uma capacidade pré-reflexiva para socorrer aquele que sofre. Piedade e bondade não eram conceitos usuais nos textos filosóficos modernos, tendo em vista suas vinculações à moral cristã e às ações de ordem privada. Rousseau e outros pensadores e moralistas setecentistas não sustentavam seus argumentos na religião nem na bondade cristã, mas na ordem da 
Natureza. Segundo Rousseau antes do desenvolvimento da razão e da reflexão os seres humanos compartilharam no hipotético estado de Natureza a sensibilidade e a piedade, um sentimento natural que refreava o amor próprio e o egoísmo. A vida em sociedade, o desenvolvimento da cultura e os frutos do conhecimento e da técnica não teriam levado os seres humanos a uma condição melhor. Somente o reencontro com a sua própria e natural bondade poderia levar a humanidade à redenção.

O pessimismo de Rousseau se expressa no "Discurso sobre a origem e os fundamentos da desigualdade entre os homens" por meio de uma crítica contundente ao racionalismo e aos princípios mais caros da Ilustração, alcançando público leitor e admirador mais amplo quando suas ideias migraram para o terreno ficcional dos romances e das suas personagens excepcionais. Estas vivem como se estivessem no Estado de Natureza, mas em sociedade, demonstrando sensibilidade pelo belo e pelo bem, tanto pela grandeza e nobreza de seu caráter quanto pelas ações compassivas voltadas aos sofredores. Rousseau não escreveu sobre a filantropia e nem foi um filantropo, afinal para sê-lo precisaria ter dinheiro e ele sempre passou por tremendas dificuldades para conseguir viver, precisando contar com a proteção de poderosos, especialmente de suas amigas da nobreza. No entanto, sua visão de mundo fundada na piedade e na sensibilidade inspirou muitos/as leitores e leitoras de seus romances a modelar-se pelo ideal da piedade e da bondade. Outros foram além da leitura dos romances e procuraram colocar em prática estes ideais compassivos, envolvendo-se com as ações filantrópicas.

No terreno da filosofia moral Adam Smith escreveu sobre a conveniência da ação, das virtudes e dos sentimentos morais como parte de um sistema moral no qual não só a razão, mas os sentimentos deviam mediar as condutas dos indivíduos nas suas relações com os outros e consigo próprios. Embora a filosofia moral não fosse matéria fácil de ser assimilada por pessoas das classes médias ou da aristocracia que não frequentavam as universidades, as ideias expressas por Adam Smith e outros filósofos contemporâneos como Francis Hutcheson e David Hume foram difundidas por meio de clérigos e de divulgadores do pensamento filosófico, de ensaios e romances, convencidos dos efeitos moralizadores e civilizadores da tolerância, 
da racionalidade e do espírito investigador, tanto na sua aplicação aos fenômenos da Natureza quanto à moral e às condutas humanas.

No livro Teoria dos Sentimentos Morais, publicado em 1759, Adam Smith principia pelo que considera ser a conveniência das ações humanas. Ele sublinha que os seres humanos têm a capacidade de imaginar e, portanto, se colocar no lugar do outro e sentir seu sofrimento. É interessante observar que um professor de filosofia moral como Smith comece seu livro pela ação voltada para aqueles que sofrem sem fazer referência à moralidade cristã e à caridade, enfatizando a capacidade humana em sentir o sofrimento alheio ou pelo menos de colocar-se no seu lugar. Smith desloca a primazia da razão como capacidade de avaliação, ponderação e julgamento, para a capacidade humana de sentir, de ser sensível aos acontecimentos que acometem os outros, afinal a sensibilidade seria, para Smith, outra dimensão da racionalidade.

Smith e seus contemporâneos, sejam romancistas ou professores de filosofia moral, procuravam imprimir no racionalismo as marcas da sensibilidade; equilibrar a reflexão com os sentimentos morais, portanto, tratava-se de sentimentos provocados e controlados pela razão. Frente ao sofrimento alheio não bastava a emoção, pois sem o controle da razão poderia levar ao afastamento, à negação em sofrer com o outro, em ser compassivo. Era necessário colocar-se racionalmente em seu lugar:

[...] sentir muito pelos outros e pouco por nós mesmos restringir nossos afetos egoístas e cultivar os benevolentes, constitui a perfeição da natureza humana; e somente assim pode produzir entre os homens a harmonia de sentimentos e paixões em que consiste toda a sua graça e propriedade (SMITH, 2002, p. 26).

A imagem do espectador sensível requer do sujeito uma capacidade ímpar, de alguém virtuoso, capaz de conhecer as causas ou os motivos pelos quais se compadece com o sofrimento alheio. Essa virtude não é algo natural, segundo Smith, mas desenvolvida pela razão e pela educação que submete o egoísmo e as paixões ingovernáveis da natureza humana. Tal virtude colocaria o espectador 
acima das pessoas vulgares e rudes, pois requer tanto conhecimento quanto sensibilidade, como suscita a beneficência, as ações que visam fazer o bem, sempre voluntárias. Pessoas benemerentes, virtuosas e superiores do ponto de vista moral e cultural, saberiam, portanto, quando e a quem fazer o bem. Adam Smith via na disposição moral individual para a beneficência um dos mais fortes remédios para as demandas sociais e políticas de uma época na qual o pauperismo e seu cortejo de sofrimentos adquiriam proporções incontornáveis para os espectadores, levando alguns deles às ações moralmente convenientes.

Motivados pela caridade ou pela filantropia - esta beneficência com pretensões universais - homens e mulheres em diferentes cidades europeias e americanas começaram a se dedicar a uma causa pública e social, o pauperismo, palavra que passou a ser cada vez mais de uso corrente, especialmente por observadores sociais. Boa parte desses agentes da benemerência foi motivada pela religião, especialmente a partir das décadas de 1830 e 1840, quando católicos e protestantes atenderam ao apelo das lideranças clericais visando à harmonização social e à reconquista de fieis, muitos deles perdidos no calor dos embates ideológicos da política revolucionária, por vezes derrotada, mas relembrada pelos movimentos e lideranças socialistas naquele período. Instituições cristãs de benemerência foram criadas com as mais diversas finalidades, desde as mais tradicionais, voltadas para a distribuição de víveres, de roupas e de atendimento aos doentes, abrigos para os sem teto, até as que intencionavam a mudança de comportamento dos pobres, como as escolas para os filhos de trabalhadores, orfanatos, reformatórios juvenis, escolas profissionais e escolas dominicais voltadas para a educação religiosa.

No entanto, o escopo da ação benemerente tornou-se muito mais amplo, envolvendo homens e um número crescente de mulheres que não foram diretamente motivados pela caridade, mas sim pelos valores civilizatórios de virtude moral da benemerência, presentes na educação das classes médias e altas. Entender as ações benemerentes e sua expansão no século XIX requer evitar a simples oposição entre o sistema da caridade e o da filantropia, afinal para boa parte das pessoas das classes privilegiadas, fossem das classes médias, fossem da aristocracia, fazer o bem era algo esperado de um bom cristão 
e de uma pessoa civilizada. Dificilmente um filantropo faria boas ações motivado somente pela razão, pois a moralidade cristã e a filosofia moral convergiam no que podemos chamar de uma ética da ação desinteressada, apesar do real interesse pelo reconhecimento e pela gratidão presentes nas relações de poder estabelecidas entre benemerentes e beneficiados. Portanto, ao tratar da filantropia, seja pelas motivações, seja pelas práticas, se faz necessário pensá-la numa sociedade de classes, sendo ao mesmo tempo referência moral das elites, mas igualmente instrumento de poder e de controle social (DONZELOT, 1986).

Caridade e filantropia motivaram um conjunto bastante diversificado de intervenções sociais que se confundiram muitas vezes com o movimento reformista, cujas proposições visavam alterações de maior amplitude, como foi o caso da regulamentação do trabalho por meio da legislação social, demanda que afrontava os valores fulcrais do livre mercado e que enfrentou feroz oposição nos parlamentos europeus ou nos poderes legislativos das nascentes repúblicas americanas, especialmente com a organização do movimento abolicionista, no qual filantropos e representantes de associações de caridade tiveram intensa participação. Além da legislação intervencionista no mercado de trabalho e da campanha abolicionista internacional a ação benemerente voltou-se para outras dimensões igualmente urgentes da questão social como a sobreposição das condições de vida das pessoas pobres com as condições sanitárias, levando à formação de associações e movimentos voltados para as moradias populares e ligas de combate às doenças infecto-contagiosas, bem como ações reformadoras de instituições prisionais, workhouses, manicômios, hospitais e reformatórios (ELLIOT, 2002; GINZBERG, 1990; GREENE, 1981; MCCARTHY, 1990).

Para dar conta de ações tão diferentes e que requeriam não só recursos financeiros, mas igualmente disponibilidade de pessoas e de tempo para colocar em prática os planos, projetos e as ações efetivas de intervenção social e institucional, foi preciso não só sensibilidade e sentimentos compassivos, mas conhecimento das realidades que deveriam ser transformadas. Nesse sentido homens e mulheres das classes privilegiadas passaram a se aproximar de pessoas e espaços que não eram os seus, visitando e observando a 
vida dos pobres de perto, situação esta que não ocorreu sem conflitos e ressentimentos de ambos os lados, afinal os sentimentos não apagavam as diferenças de classe, mesmo para os corações mais bem intencionados.

Alguns contemporâneos criticaram duramente essa aproximação do mundo dos pobres por parte dos filantropos, porque muitos deles desejavam impor seus valores e mudar a forma como as pessoas pobres viviam, impondo padrões de conduta, especialmente de conduta moral, intrometendo-se na educação das crianças, na organização do trabalho doméstico e no cotidiano. Para alguns desses críticos, como o escritor Charles Dickens, havia um aspecto nada louvável na filantropia, fosse de inspiração cristã ou não, que era a prepotência e a arrogância devidas ao preconceito de classe, que tornava inócua a ação pretensamente benemerente, embora Dickens tivesse apoiado muitas iniciativas filantrópicas, inclusive uma instituição de regeneração para mulheres decaídas, idealizada e mantida por uma amiga sua, a condessa Angela Bourdett-Coutts, filantropa muito reconhecida na Inglaterra vitoriana. ${ }^{4}$

As críticas não vieram somente dos escritores e periodistas que mesmo reconhecendo as boas intenções e as motivações sinceras de muitos filantropos, perceberam que a extensão numerosa da caridade e da filantropia, em particular entre as mulheres das classes médias, criava uma situação de agravamento da humilhação dos pobres e de ressentimento de classe. Entre os socialistas a crítica assumia fortes tonalidades políticas, pois interpretaram a extensão da filantropia como um instrumento das classes proprietárias para pacificar os trabalhadores com suas benesses paliativas - chamadas sempre pejorativamente de esmolas -, disseminando valores cristãos como a resignação e humildade, arrefecendo o ímpeto político da luta de classes e da revolução. Este é o tom da crítica de Engels ao humanitarismo cristão da burguesia inglesa:

Os ricos ingleses não pensam nos pobres, eles que construíram estabelecimentos de beneficência como não se vêem em qualquer outro país? Sem dúvida, estabelecimentos de beneficência! Como se fosse ajudar o proletário começar por explorá-lo até a medula, para poder em seguida lançar 
sobre ele com compaixão e farisaísmo o vosso prurido de caridade e para vos apresentardes ao mundo como grandes benfeitores da humanidade, quando dão a esse infeliz, que sugaram até o sangue, a centésima parte do que pertence. Beneficência que rebaixa ainda mais quem a pratica do que quem a recebe; beneficência que lança ainda mais na lama o infeliz que espezinharam, que faz com que o pária desumanizado, excluído da sociedade, renuncie primeiro à última coisa que lhe resta, à sua condição de homem, e comece por mendigar o perdão à burguesia, antes que ela lhe conceda a mercê de lhe imprimir na testa, dando-lhe uma esmola, o selo da degradação! (ENGELS, 1985, p. 313).

Tocqueville também foi um crítico da filantropia, particularmente do que ele chamava de "caridade pública", embora compartilhasse das idéias de Rousseau sobre os sentimentos morais e a capacidade de colocar-se no lugar daqueles que sofrem. Em suas viagens pela América e pela Inglaterra ele percebeu o quanto o fenômeno do pauperismo fomentava a filantropia e segundo sua interpretação, fomentava igualmente a dependência dos necessitados. Tocqueville viu no processo de expansão da filantropia não a expressão do altruísmo nas sociedades inglesa e norte-americana, nem um processo de identificação com o sofrimento alheio, mas de alteridade, de afastamento e de dependência. A filantropia não seria uma prática de altruísmo, mas de individualismo e de amor próprio, pois quando olhava para o pobre ou para aquele que sofre o filantropo não o fazia por caridade ou por compaixão, mas porque estabelecia uma relação de negação, de não querer ser como ele. Tocqueville via na filantropia pública um espetáculo do amor próprio e não uma ação desinteressada a alguém igual na sua humanidade (TOCQUEVILLE, 1997; WILHELM, 2007).

Apesar das críticas mais ou menos contundentes, nas sociedades capitalistas e em processo de industrialização a questão social passou a ser objeto de uma ação política das classes privilegiadas e também do Estado, embora a intervenção do Estado no século XIX fosse muito restrita e em certos países realmente ínfima, ficando à mercê das associações de caridade e de filantropia. 
O que estamos a chamar de ação política foi interpretado diferentemente pelos contemporâneos, pela historiografia e pelo pensamento social. Para os críticos oitocentistas da filantropia e da caridade como Engels, Tocqueville ou mesmo Dickens a questão tinha uma dimensão política porque criava a dependência dos necessitados e reforçava o lugar moral de onde os filantropos podiam interferir na vida dos pobres, muitas vezes de maneira arrogante e sem nenhum ideal altruísta a não ser reforçar a hierarquia entre ricos e pobres, entre superiores e inferiores.

A crítica liberal e a crítica marxista às boas intenções da filantropia e do amplo sistema da caridade, mesmo estando em pólos opostos, acabaram por criar um estereótipo da benemerência associado à arrogância de classe, ao sentimento de superioridade ou ao estímulo à dependência dos beneficiados. O problema é que o estereótipo não ajuda a entender a dimensão política da caridade e da filantropia no século XIX, nem as suas diferenças, afinal a filantropia passou a se distinguir da caridade porque seu raio de ação ia muito além da questão social, abrangendo a proteção às artes e à cultura, a criação e manutenção de escolas e universidades, proteção à natureza, além de várias ações voltadas para a proteção e o bem estar dos animais, especialmente na Inglaterra e nos Estados Unidos.

É preciso entender a extensão da benevolência no século XIX para além dos adjetivos pejorativos e da explicação marxista da dominação de classe, embora tenhamos que concordar que foi uma das suas dimensões políticas, mas não exclusiva, afinal não se pode esquecer que a benemerência também foi praticada pelas pessoas das classes trabalhadoras, embora seja uma forma menos conhecida de assistência aos necessitados, mas não menos importante.

Uma possibilidade de sairmos desse imbróglio é pensar a caridade, a filantropia e a sua expansão no século XIX, como processos políticos impulsionados pelos sentimentos de piedade e de bondade, reforçando hierarquias sociais, estabelecendo códigos de civilidade e de dominação, mas também criando espaços de subjetivação pelo protagonismo público e pela agência, em especial por parte das mulheres, que ao longo dos séculos XIX e XX passaram a desempenhar um importante papel de organizadoras e mantenedoras de associações de caridade e de filantropia, criando 
um espaço de poder, afinal elas não tinham direitos de cidadania e estavam impedidas legalmente de ter acesso ao mundo público $\mathrm{da}$ política formal ou institucional. $\mathrm{O}$ fenômeno social da benevolência apresenta-se, portanto, como uma oportunidade para se pensar na política dos sentimentos ou numa mobilização política dos sentimentos na forma como a questão social foi problematizada pelos filantropos/as e agentes da caridade.

\section{A política da piedade e dos sentimentos}

A questão social tem sido problematizada pela bibliografia citada como um desdobramento das tensões e contradições do capitalismo industrial. A organização racional do trabalho, o parcelamento das atividades laborais e o controle sobre o tempo dentro e fora das fábricas ao mesmo tempo em que foram instrumentos das novas relações de produção que incrementaram ganhos extraordinários, expandindo a riqueza em níveis absolutamente inéditos na história do Ocidente, produziram aqueles quadros de miséria que tanto chocaram observadores e críticos da época.

A dramaticidade com a qual se revestiu a questão social no século XIX se deu em grande parte porque a miséria ou o pauperismo atingiam de forma ainda mais dura justamente os trabalhadores, aqueles que pela ideologia liberal deveriam e poderiam viver com seus salários para se manter trabalhando. $\mathrm{O}$ incômodo moral é que não houvera só um aumento de mendigos, inválidos e doentes, alvos do velho sistema da caridade, mas sim a constatação do brutal empobrecimento dos trabalhadores em meio à riqueza. Parafraseando Hannah Arendt, a questão social conforme se configura no capitalismo industrial passou a se referir à própria existência da pobreza, crescentemente sinônimas. Conforme expusemos, o problema não era a existência da mendicidade, mas sim da pobreza dos trabalhadores. Acompanhando o pensamento de Arendt:

Pobreza é mais do que privação, é um estado de constante carência e aguda miséria, cuja ignomínia consiste em sua força desumanizadora; a pobreza é abjeta, porque submete 
os homens ao império absoluto de seus corpos, isto é, ao império absoluto da necessidade, como todos os homens a conhecem a partir de sua experiência mais íntima independente de todas as especulações (ARENDT, 1988, p. 48).

Por ora nos interessa retomar um argumento presente na análise de Hannah Arendt, a introdução dos sentimentos compassivos na teoria e na prática políticas a partir do contexto das revoluções modernas. Em parte oriundas do vocabulário rousseauísta, as palavras piedade, amor, compaixão e bondade passaram a circular de forma bastante elástica na linguagem, enunciadas pelos revolucionários e socialistas, mas também pelos cristãos das mais variadas confissões religiosas, pelos humanistas liberais como Stuart Mill e por mulheres sensibilizadas pelas mais variadas causas do sofrimento da humanidade. Sentir pena dos miseráveis passou a ser uma experiência sentimental compartilhada por diferentes agentes, dos mais revolucionários aos mais conservadores, levando a uma política da piedade. Ao distinguir a piedade da solidariedade Arendt diz que esta é uma alternativa à piedade, estabelecendo os homens uma comunidade de interesses com os miseráveis em favor de valores como a grandeza e a dignidade humanas. A solidariedade pode ser suscitada pelo sofrimento dos miseráveis, mas por ser racional não se deixa guiar por ele. Diferentemente,

[...] sem a presença do infortúnio, a piedade não pode existir e, portanto, tem exatamente o mesmo interesse na existência dos infelizes, que a sede de poder na existência dos fracos. Ademais, por se tratar de um sentimento, a piedade pode encontrar em si mesma, o seu próprio prazer, e isso leva, quase que automaticamente, a uma glorificação de sua causa, que é o sofrimento alheio (ARENDT, 1988, p. 70-71).

Arendt se refere a uma questão pouco explorada pela historiografia que tratou da expansão da benevolência no século XIX, a saber, sua dimensão política, ou colocando em outros termos, a organização de uma política dos sentimentos no enfrentamento da questão social. Uma aproximação do tema tem sido feita desde a década de 1980 ao 
se buscar compreender o novo papel desempenhado pelos Estados modernos, particularmente pelos Estados nacionais que começaram a desenhar políticas sociais para atender a insegurança econômica e a ausência de mecanismos legais eficazes para a proteção dos fracos, dos impotentes, dos necessitados e dos trabalhadores (SKOCPOL, 1985; GORDON, 1995). Entretanto, boa parte dos estudos sobre o Estado do Bem Estar foi construída a partir de dois grandes blocos analíticos: a abordagem institucional, tratando da reconfiguração dos Estados e das políticas de bem estar; e a abordagem da história social, mais voltada para entender as relações estabelecidas entre agentes públicos, programas e ações de bem estar e os beneficiários das políticas sociais, bem como seus fundamentos ideológicos. $\mathrm{Ou}$ seja, a dimensão política tem sido circunscrita às análises sobre o Estado, a ideologia e o controle social (ALVES, 2014).

Aproximar-se de Arendt e de outros investigadores sociais contemporâneos abre caminho para uma abordagem sobre as dimensões políticas da questão social, especialmente em se tratando da expansão da benevolência e das ações caritativo-filantrópicas. Pierre Ansart (2007) lembra que na análise política geralmente os sentimentos são considerados secundários, mais como consequências do que fatos e motivações. Quando são considerados estão associados às convulsões sociais, aos momentos excepcionais como revoltas, revoluções, situações coletivas de crise ou de ruptura. Continuando com Ansart, as análises históricas e sociais dos sentimentos são reveladoras igualmente dos processos, das permanências, das continuidades, cabendo à História compreender as diferentes configurações dos sentimentos e as suas transformações.

Seguindo a orientação deste autor ajustamos o foco da discussão novamente para a questão social conforme se apresentava no século XIX aos homens e mulheres sensibilizados pelo sofrimento dos pobres e pelo crescente pauperismo. Defendemos que esta sensibilidade não foi motivada tão somente pelos afetos individuais e desinteressados de corações piedosos, mas sim a expressão de um conjunto de sentimentos compartilhados por indivíduos das classes mais privilegiadas e também por indivíduos das classes trabalhadoras, que os motivaram à ação política de gerenciamento do social. Certamente que esta ação política não se deu ao contrapelo das 
políticas sociais propostas pelos Estados, ao contrário, estiveram articuladas e algumas vezes se sustentaram mutuamente.

Queremos salientar outra dimensão das ações políticas relativas à questão social, sejam elas estatais, sejam de natureza privada, por intermédio das organizações caritativas e filantrópicas. As palavras podem nos servir de guia, afinal compunham o léxico compassivo tanto para as ações de motivação laica, quanto para aquelas de franca motivação religiosa: piedade, bondade, compaixão, simpatia, comiseração, todas expressões do sentimento ou da sensibilidade pelo sofrimento e pelos sofredores que não partilhavam das benesses da riqueza e da abundância, mesmo que partícipes da sua produção, como era o caso dos trabalhadores. As palavras enunciavam múltiplas ações que a princípio visavam mitigar os sofrimentos, apresentando uma face da ação compassiva; entretanto, as palavras não estabelecem uma relação de transparência entre a intenção e o gesto compassivo, adquirindo outros significados para aqueles que as usavam livremente na justificativa de suas ações e para os seus destinatários.

Recorrendo à análise proposta por Myriam D’Allones (2008) o léxico compassivo não foi expressão somente de sentimentos isolados ou compartilhados, mas de uma ação política inspirada e justificada pela sensibilidade ao sofrimento dos outros. Portanto, um primeiro elemento da política dos sentimentos é a consciência da alteridade a quem os atos e as intenções são direcionadas. D’Allones refere-se ao contexto político das sociedades liberais fundadas no ideário democrático da igualdade, como os Estados Unidos e a Inglaterra de meados do século XIX, mas podemos observar a expansão deste ideário para outros contextos, como é o caso da França e também das nascentes repúblicas americanas. Diferentemente das sociedades do Antigo Regime as experiências republicanas e das monarquias constitucionais oitocentistas começaram a operar com um imaginário político fundado na indiferenciação e indistinção, sendo todos, a princípio, cidadãos nos marcos do ordenamento jurídico da sociedade. No entanto, conforme a autora, as "pequenas diferenças" individuais e as não tão pequenas assim, como as diferenças de classe, fomentaram o individualismo e a tendência ao isolamento dos indivíduos entre os seus pares, ampliando o fosso emocional e 
social entre estes e a alteridade dos pobres. Daí, portanto, a tensão constituinte daquele imaginário político: tensão entre a universalização republicana e democrática e a singularização das diferenças e das distinções sociais.

É nesse território que os sentimentos compassivos passam a adquirir um significado político: a identificação com aquele que sofre levava à ação, mas esta não aproximava iguais, pelo contrário, seu intento não era alcançar a justiça social, pelo menos não para a maioria das pessoas que se envolveram com as ações caritativofilantrópicas. A ação política sobre o social - esta invenção das sociedades ocidentais do século XIX - é paradoxal, como mostra D’Allones reverberando Arendt. Ao mesmo tempo em que a ação se expande, ganhando em extensão, tanto numérica quanto pela variedade de seus objetos, os laços afetivos supostamente estabelecidos pelos sentimentos compassivos se afrouxam, pois não reintegram os miseráveis, os excluídos da ordem social e de suas benesses. A espetacularização dos sentimentos compassivos fortaleceu ainda mais a linha divisória entre os que tinham o poder de dispensar cuidados e aqueles que precisam recebê-los.

O segundo elemento da política dos sentimentos é a tendência à crescente indiferenciação entre o social e o político; entre o público e o privado, ou como bem observou Hannah Arendt: "No mundo moderno as duas esferas constantemente recaem uma sobre a outra, como ondas no perene fluir do próprio processo da vida.” (ARENDT, 1989, p. 43). A ascensão do social ao domínio do político significou que o enfrentamento da necessidade que até a modernidade havia sido restrito ao mundo da família ou da piedade cristã, passava doravante a ser uma questão política, ou seja, a questão social entrava na cena política, fosse por meio das políticas sociais, fosse pela ação caritativo-filantrópica. Esta, por sua vez, não deveria aparecer sob a mesma luz da ação política, afinal suas motivações eram ou deviam ser outras: a bondade, a caridade, o gesto desinteressado. No entanto, suas ações não se deram no vácuo ou na ausência de interesses. As ações benevolentes e compassivas, motivadas ou não pela religião, tinham a sua racionalidade, expressa pela organização e mobilização de recursos humanos e financeiros, por um rígido código moral e pela finalidade mitigatória, senão 
mesmo reformista. Ou seja, os sentimentos compassivos, como a piedade e a bondade, quando emergem à luz da vida pública ou, como disse Arendt, quando saem de seu esconderijo para assumir um papel público, se transformam em instrumentos políticos, fontes de poder para seus dispensadores e de submissão para os necessitados. Segundo a análise crítica de Arendt a invasão dos sentimentos na esfera pública e na política desloca a liberdade em favor da necessidade; os cidadãos em favor dos oprimidos ou dos necessitados, ao mesmo tempo em que os indivíduos que promovem a benevolência passam a exercer um papel político não representativo; um papel político difuso na vida social. Este papel político se fundamenta no poder moral da bondade e na extensão política dos sentimentos compassivos para a esfera pública que, por sua vez, dão visibilidade ao poder de fazer o bem.

Todavia, não nos alinhamos totalmente à crítica de Arendt à ascensão dos sentimentos na esfera pública e no domínio da política. Partimos da percepção de que a política é ação e discurso e no período que abarca os séculos XIX e XX ela sofreu mutações deveras significativas, a começar por sua amplitude, abarcando a questão social, mas igualmente o aparecimento de novos sujeitos na reconfiguração da vida ativa e política. Concordamos com D’Allones quando ela diz que a questão social se tornou irreversível e fundamental para o campo político. As leis sociais que regulamentaram o trabalho dificilmente podem ser interpretadas como reduzidas à necessidade, num campo apartado da liberdade. Leis de seguridade que estabeleceram várias formas de proteção aos trabalhadores e às trabalhadoras não os reduziram à humilhação ou à degradação, pelo contrário, foram conquistas indissociáveis do acesso à cidadania, que por sua vez, não é um lugar ou uma condição acabada e limitada. As mulheres trabalhadoras, por exemplo, não foram equiparadas no exercício da cidadania aos homens trabalhadores, ampliando seus direitos civis e políticos bem mais tarde, somente no século XX. No contexto do capitalismo industrial as lutas sociais foram lutas políticas que não devem ser subestimadas ou negligenciadas pela memória histórica.

Neste processo é preciso estabelecer as diferenças entre uma política dos sentimentos formada por linhas hierárquicas demarcatórias entre o poder dos benevolentes e a impotência dos necessitados; 
e uma política dos sentimentos que possibilitou a solidariedade e a agência dos sujeitos. A compreensão da pluralidade das ações políticas pode, portanto, ser um elemento fundamental para se entender as múltiplas dimensões da benevolência, como suas motivações, seus agentes e seus desdobramentos políticos e sociais.

Uma dessas dimensões que mereceria uma análise mais demorada seriam as relações entre a ideologia de gênero e o gerenciamento da questão social. Sabemos que a organização da caridade e da filantropia na modernidade envolvia homens e mulheres. Todavia, a história das mulheres mostrou que a partir do século XVIII e especialmente ao longo do século XIX uma mudança significativa ocorreu devido à política de gênero da modernidade, fundada na separação das esferas pública e privada e nas tentativas de exclusão das mulheres da esfera pública baseada no determinismo naturalista. $\mathrm{O}$ forte tom ideológico que predominou nos discursos sobre as esferas adequadas para cada sexo estabeleceu um lugar bastante limitado para as mulheres nos quadros da vida privada como esposa e mãe, colocando empecilhos cada vez maiores para a presença pública e a autonomia, demandas políticas que já vinham de uma tradição radical do pensamento e da escrita de mulheres desde o século XVIII (MIRANDA, 2010).

A ideologia de gênero e a reclusão à domesticidade em muito podaram as ambições femininas de ação pública, mas por outro lado abriram algumas possibilidades de agência ao ressaltar as virtudes femininas como a bondade e uma suposta predisposição natural para os cuidados com os necessitados, sejam os mais próximos da família, sejam aqueles que tradicionalmente estavam associados ao domínio da caridade cristã, os mendigos, os doentes, os incapacitados. Segundo Martins foi "[...] a partir de uma política de gênero que excluiu as mulheres do mundo público que se definiu a assistência como um gênero de trabalho feminino que não atentaria contra a moral e a virtude das mulheres." (MARTINS, 2011, p. 22). Apesar de seu caráter excludente e limitador a ideologia de gênero acabou por criar espaços de ação social e, posteriormente, de ação política para as mulheres, resultado do processo histórico de deslizamento dos cuidados dispensados na esfera privada para a expansão dos sentimentos benevolentes à esfera pública. 
Estas considerações nos levam a afirmar que a ação política das mulheres precisa ser revista historicamente, algo que não podemos fazer neste artigo, mas que gostaríamos de lembrar, mesmo que brevemente. A história das mulheres e a memória histórica feminista atribuíram à mobilização pelos direitos civis e políticos no século XIX os inícios da ação política e pública das mulheres. Certamente esse foi um marco muito importante na elaboração de um discurso mais ou menos coeso e crítico quanto à organização social e política de gênero altamente excludente, no entanto, não foi o único caminho trilhado pelas mulheres.

A política dos sentimentos no enfrentamento da questão social teve nas mulheres participantes ativas, tanto no que diz respeito à reprodução de relações de dominação, mas também como uma forma de enveredar pelos caminhos da crítica e da consciência social, exercendo um protagonismo público que pela política formal dos partidos e da representação não teriam conseguido (MCCRONE, 1976). Talvez a dimensão de gênero seja uma das formas mais significativas assumida pela política dos sentimentos, desdobrando-se entre a dominação e a passividade; entre a agência e o protagonismo público.

\section{Considerações finais}

Até as décadas de 1980 e 1990 a caridade e a filantropia frequentaram de forma pontual as páginas dos livros e artigos dos historiadores sociais, especialmente aqueles de orientação teórica marxista, geralmente como indício do controle social ou de dominação da burguesia. Entretanto, outros estudos, em especial aqueles que passaram a dar atenção para o protagonismo público das mulheres por meio da caridade e da filantropia, passaram a tratar essas práticas benemerentes a partir de um corpo documental mais amplo e diversificado, abrangendo os registros das instituições caritativo-filantrópicas, escritos pessoais de homens e mulheres envolvidos com a benemerência, relatórios oficiais e também a escrita literária e ensaística, com suas variantes críticas e encomiásticas ao "surto" de bondade. 
Nas percepções coevas produzidas pelos observadores a benemerência não tinha e não deveria ter associação com os interesses políticos. Suas motivações deviam ser outras, como as virtudes, tanto aquelas que faziam parte do vocabulário religioso, como aquelas descritas e valorizadas pelo discurso filosófico. Neste artigo procuramos expandir as leituras realizadas sobre as práticas benemerentes, ainda tão presentes em nosso cotidiano como expressões do humanitarismo e da solidariedade com os que sofrem. Não defendemos que por trás de cada gesto humanitário ou caritativo-filantrópico dos homens e mulheres do passado estivesse sorrateiramente o interesse individual e de dominação de classe, embora fossem experiências de poder. Esta leitura "interessada" da caridade e da filantropia não deixa de ser uma interpretação fundamentada historicamente, contudo, afirmamos que não foi exclusiva e nem sempre esteve à frente das intenções e das realizações.

Somente a atenção às singularidades históricas poderá autorizar as interpretações políticas de um fenômeno até muito recentemente considerado tão somente pelo viés da tutela e da dominação de classe. Nesse sentido, este artigo propôs ainda duas outras vertentes de problematização para a benemerência. Primeiro, deslocar os sentimentos compassivos associados àquelas práticas do terreno isolado das sensibilidades ou do "interesse", para pensá-los como parte de uma política, ou de um conjunto de práticas de gerenciamento das alteridades que compunham a chamada questão social. Por último, mesmo que não tenha sido o foco desta análise, apontamos para outra problematização política da benemerência que é a sua dimensão de gênero. $O$ poder da benevolência não foi neutro, especialmente a partir do século XIX, quando um contingente muito expressivo de mulheres passou a se envolver com a filantropia e a caridade. Registros de variados tipos anotaram essa verdadeira feminilização da filantropia, processo histórico que em nossa interpretação é indissociável da política dos sentimentos, que por sua vez representou uma vereda respeitável e legítima de protagonismo público e de exercício de poder das mulheres das classes mais privilegiadas. 


\section{THE POLICY OF FEELINGS AND THE SOCIAL ISSUE IN THE 19TH CENTURY}

Abstract: The article analyses the social issue as defined in the 19th Century by philanthropy, from the collective mobilization and the policy of feelings. It seeks to understand the different motivations of speeches and reformer and benevolent practices, trying to rebuild their social and moral foundations, articulated to a reflection on the political feelings triggered in the confrontation of the social issue.

Keywords: Philanthropy. Charity. Feelings. Power. Social issues.

\section{Notas}

${ }^{1}$ Este artigo é resultado de pesquisa desenvolvida como Bolsista de Produtividade do CNPq (2012-2015).

${ }^{2}$ Há 11 anos a ONU estabeleceu junto com 191 países os Objetivos de Desenvolvimento do Milênio, com prazo de alcance até 2015. São oito as metas a serem alcançadas: erradicar a pobreza extrema e a fome; atingir o ensino básico fundamental; promover a igualdade de gênero e a autonomia das mulheres; reduzir a mortalidade infantil; melhorar a saúde materna; combater o HIV/ AIDS e outras doenças infecto-contagiosas; garantir a sustentabilidade ambiental; estabelecer parcerias para o desenvolvimento. Cf. www.pnud.org.br.

${ }^{3}$ As telas citadas podem ser visualizadas em: 〈www.pinterest.com>.

${ }^{4} \mathrm{O}$ folheto escrito por Dickens em 1849, An appeal to fallen women (Apelo às mulheres decaídas), era para ser distribuído entre as mulheres presas por prostituição com a finalidade de que elas procurassem a instituição regeneradora criada por ele e por sua amiga filantropa, a condessa Bourdett-Coutts. Disponível em: 〈http://dickens.jp/etexts/dickens/others/sonota/fallen.pdf〉. Acesso em: 10 maio 2015.

\section{Referências}

ALVES, Ismael Gonçalves. (Re)construindo a maternidade: as políticas públicas materno-infantis brasileiras e suas implicações na Região Carbonífera Catarinense (1920-1960). Tese (Doutorado em História)-Programa de Pós-Graduação em História da Universidade Federal do Paraná, Curitiba, 2014.

AQUINO, Tomas de. Suma Teológica. Salamanca: Universidad Pontifícia de Salamanca, 1990. 
ARENDT, Hannah. Da Revolução. São Paulo; Brasília: Editora Ática; EDUNB, 1988.

. A condição humana. Rio de Janeiro: Forense Universitária, 1989.

ANSART, Pierre. Sciences socials et sentiments politiques. In: ANSART, Pierre; HAROCHE, Claudine. Les sentiments et le politique. Paris: L'Harmattan, 2007.

BARTHES, Roland. Literatura e realidade: o que é o realismo? Lisboa: Publicações Dom Quixote, 1984.

BRIGGS, Asa. The Age of Improvement (1783-1867). New York: Routledge, 1999.

D’ALLONES, Myriam Revault. L'homme compassionel. Paris: Éditions Seuil, 2008.

DUPRAT, Catherine. Le temps des philanthropes. La philanthropie parisienne des Lumières à la monarchie de Juillet. Paris: Éditions du CTHS, 1993.

ELLIOT, Dorice Williams. The angel out of the house. Philanthropy and gender in Nineteenth Century England. Charlottesville and London: University Press of Virginia, 2002.

ENGELS, F. A situação da classe trabalhadora na Inglaterra. São Paulo: Global Editora, 1985.

GEREMEK, Bronislaw. A piedade e a forca. História da miséria e da caridade na Europa. Lisboa: Terramar, 1995.

. Os filhos de Caim: vagabundos e miseráveis na literatura européia. 1400-1700. São Paulo: Companhia das Letras, 1995.

GINZBERG, Lori D. Women and the work of benevolence: morality, politics and class in the Nineteenth Century United States. New Haven: Yale University Press, 1990. (Yale Historical Publications Series).

GOHN, Maria da Glória Marcondes. O protagonismo da sociedade civil. Movimentos sociais, ONG’s e redes solidárias. São Paulo: Editora Cortez, 2003.

. Ações coletivas civis na atualidade: dos programas de responsabilidade/ compromisso social às redes de movimentos sociais. Ciências Sociais UNISINOS, São Leopoldo, v. 46, n. 1, p. 10-17, jan./abr. 2010.

GORDON, Linda. Pitied but not entitled. Single mothers and the history of welfare. Cambridge: Harvard University Press, 1995.

GREENE, Dana. Quaker feminism: the case of Lucretia Mott. Pennsylvania History, v. 48, n. 2, abr. 1981, p. 143-154. Disponível em: <http://www.jstor.org/ stable/27772738>. Acesso em: 20 jul. 2015. 
HIMMELFARB, Gertrud. La idea de la pobreza: Inglaterra a princípios de la era industrial. Mexico: Fondo de Cultura Económica, 1988.

HOBSBAWN, Eric. A Era do Capital: 1848-1875. São Paulo: Paz e Terra, 1997. . Da revolução industrial inglesa ao imperialismo. Rio de Janeiro: Forense Universitária, 2000.

MARTINS, Ana Paula Vosne. Gênero e assistência: considerações históricoconceituais sobre práticas e políticas assistenciais. História, Ciências, Saúde - Manguinhos, Rio de Janeiro, supl. 1, v. 18, p. 15-34, dez. 2011.

MCCRONE, Kathleen E. Feminism and philanthropy in Victorian England: the case of Louisa Twining. Historical Papers/Communications Historiques, v. 11, n. 1, p. 123-139, 1976. Disponível em: 〈http://id.erudit.org/ierudit/030807ar〉. MIRANDA, Anadir dos Reis. Mary Wollstonecraft e a reflexão sobre os limites do pensamento liberal e democrático a respeito dos direitos femininos. 17591797. Dissertação (Mestrado em História)-Universidade Federal do Paraná, Curitiba, 2010. $155 f$.

POLANY, Karl. A grande transformação: as origens da nossa época. Rio de Janeiro: Elsevier, 2000.

ROUSSEAU, Jean-Jacques. Discurso sobre a origem e os fundamentos da desigualdade entre os homens. Rio de Janeiro: Ediouro, 2000.

SKOCPOL, Theda (Ed.). Bringing the State back in. Cambridge: Cambridge University Press, 1985.

SMITH, Adam. Teoria dos sentimentos morais. São Paulo: Martins Fontes, 2002. TOCQUEVILlE, Alexis de. Memoir on pauperism. London: Civitas, 1997.

THOMPSON, E. P. A formação da classe operária inglesa. 3 v. São Paulo: Paz e Terra, 1987.

WILHELM, Patrice. Sympathie et douceur démocratique. In: ANSART, Pierre; HAROCHE, Claudine. Les sentiments et le politique. Paris: L'Harmattan, 2007.

Recebido em: 17/06/2016

Aprovado em: 15/03/2017 